\title{
In reply: Uncertainty in the methods and interpretation of a meta- analysis of airway complications from lidocaine lubrication
}

\author{
Alan Hsi-Wen Liao, MBChB (D) Shang-Ru Yeoh, MD, MS • Yu-Cih Lin, RN, NA, PhD • \\ Fai Lam, MD, MS • Ta-Liang Chen, MD, PhD • Chien-Yu Chen, MD, PhD
}

Received: 11 May 2020/Revised: 11 May 2020/Published online: 26 May 2020

(c) Canadian Anesthesiologists' Society 2020

\section{To the Editor,}

We would like to thank Dr. Kataoka for showing interest in our study ${ }^{1}$ and raising a few important and relevant comments regarding our research. As Dr. Kataoka pointed out, ${ }^{2}$ several methodological limitations exist and may have influenced the outcome of our analyses. We would like to take the opportunity to address these.

First, our statistical calculation was done using RevMan software, which is provided by the Cochrane Collaboration. Its unique integrated hybrid method of combining the DerSimonian and Laird method with the Mantel-Haenszel method for random effect calculation has been implemented for many years, and the details can be found in the Cochrane Handbook for Systematic Reviews of Interventions Section 10.10.4.4. ${ }^{3}$

Alan Hsi-Wen Liao and Shang-Ru Yeoh contributed equally to this work.

This reply is related to letter $20-00365$.

A. H.-W. Liao, MBChB $\cdot$ S.-R. Yeoh, MD, MS

Department of Anesthesiology, Taipei Medical University

Hospital, Taipei, Taiwan

Y.-C. Lin, RN, NA, PhD

Department of Anesthesiology, Taipei Medical University

Hospital, Taipei, Taiwan

School of Nursing, College of Nursing, Taipei Medical

University, Taipei, Taiwan

F. Lam, MD, MS

Department of Anesthesiology, Taipei Medical University

Hospital, Taipei, Taiwan

Institute of Public Health, College of Public Health, Taipei Medical University, Taipei, Taiwan
Second, we would like to disclose that our Egger's test was performed using Comprehensive Meta-Analysis (CMA) software (version 2.0, Biostat Inc., Englewood, NJ, USA).

Third, we concur with Dr. Kataoka's interpretation that our trial sequential analysis may be a "false negative" due to bias. Indeed, because of the limited study sample, a conclusion regarding the benefit of lidocaine lubrication is not possible at present. Nevertheless, as the calculated required information size is well over 7 million, we maintain our doubt regarding the feasibility of conducting future trials with that sample size.

Fourth, selection bias was noted in seven of the primary studies, including Kori et al. ${ }^{4}$ as was disclosed in Fig. 2 of our study. Kori et al.'s data were only included in the postoperative hoarseness (PH)-24 hr analysis, and thus we have re-calculated the $\mathrm{PH}-24 \mathrm{hr}$ result, which remained unchanged after Kori et al.'s exclusion (original risk reduction [RR], $0.91 ; 95 \%$ confidence interval [CI], 0.66 to

T.-L. Chen, MD, PhD

Department of Anesthesiology, School of Medicine, College of Medicine, Taipei Medical University, Taipei, Taiwan

Department of Anesthesiology, Wan Fang Hospital, Taipei, Taiwan

C.-Y. Chen, MD, PhD ( $\square)$.

Department of Anesthesiology, Taipei Medical University

Hospital, Taipei, Taiwan

e-mail: jc2jc@tmu.edu.tw

Department of Anesthesiology, School of Medicine, College of Medicine, Taipei Medical University, Taipei, Taiwan

Graduate Institute of Humanities in Medicine, Taipei Medical University, Taipei, Taiwan 
Table 1 Sensitivity analyses: the effect of potential bias of control group on primary and secondary outcomes

\begin{tabular}{|c|c|c|c|c|c|c|}
\hline $\begin{array}{l}\text { Potential bias or } \\
\text { limitations } \\
\text { excluded }\end{array}$ & $\begin{array}{l}\text { POST within } 1 \mathrm{hr} \\
\operatorname{RR}(95 \% \mathrm{CI}), I^{2}\end{array}$ & $\begin{array}{l}\text { POST within } 24 \\
\text { hr RR }(95 \% \mathrm{CI}) \\
I^{2}\end{array}$ & $\begin{array}{l}\text { POSTMS within } 1 \\
\text { hr RR }(95 \% \text { CI }), I^{2}\end{array}$ & $\begin{array}{l}\text { POSTMS within } 24 \\
\text { hr RR }(95 \% \mathrm{CI}), I^{2}\end{array}$ & $\begin{array}{l}\text { Cough within } 24 \\
\text { hr RR }(95 \% \text { CI }), \\
I^{2}\end{array}$ & $\begin{array}{l}\text { Hoarseness within } \\
24 \mathrm{hr} \text { RR }(95 \% \mathrm{CI}) \\
I^{2}\end{array}$ \\
\hline & $\begin{array}{r}1.11(0.82 \text { to } \\
1.51), 77 \%\end{array}$ & $\begin{array}{l}0.99(0.8 \text { to } 1.17) \\
33 \%\end{array}$ & $\begin{array}{l}1.06(0.37 \text { to } 3.02) \text {, } \\
59 \%\end{array}$ & $\begin{array}{l}0.49(0.16 \text { to } 1.50) \\
28 \%\end{array}$ & $\begin{array}{l}1.09(0.71 \text { to } 1.66) \\
23 \%\end{array}$ & $\begin{array}{l}0.91 \text { (0.66 to } 1.24) \text {, } \\
1 \%\end{array}$ \\
\hline \multicolumn{7}{|c|}{ Methodology_Control group } \\
\hline $\begin{array}{l}\text { No lubrication } \\
\text { only* }\end{array}$ & $\begin{array}{r}1.08(C \\
1.46\end{array}$ & $\begin{array}{r}0.98(0 \\
1.27)\end{array}$ & $\begin{array}{l}0.83(0.22 \text { to } 3.13) \\
\quad 67 \%\end{array}$ & $\begin{array}{l}0.33(0.08 \text { to } 1.35) \\
25 \%\end{array}$ & $\begin{array}{r}1.16 \\
2.7\end{array}$ & $\begin{array}{l}0.86(0.61 \text { to } 1.21) \\
9 \%\end{array}$ \\
\hline $\begin{array}{l}\text { No lubrication } \\
\text { and others }\end{array}$ & $\begin{array}{r}1.17(0.89 \text { to } \\
1.55), 64 \%\end{array}$ & $\begin{array}{c}1.08(0.80 \text { to } \\
1.45), 0 \%\end{array}$ & $\begin{array}{l}0.26(0.00 \text { to } \\
19.15), 88 \%\end{array}$ & $\begin{array}{l}0.16(0.01 \text { to } 2.05) \\
48 \%\end{array}$ & $\begin{array}{l}1.27(0.08 \text { to } \\
19.10), 68 \%\end{array}$ & $\begin{array}{l}0.68(0.26 \text { to } 1.77) \\
13 \%\end{array}$ \\
\hline
\end{tabular}

$\mathrm{CI}=$ confidence interval; POST $=$ postoperative sore throat; POSTMS $=$ moderate to severe postoperative sore throat; RR $=$ relative risk

*With no lubrication only: Basaranoglu et al., ${ }^{5}$ Klemola et al., ${ }^{6}$ Kori et al. ${ }^{4}$

With no lubrication and others: Basaranoglu et al., ${ }^{5}$ Klemola et al., ${ }^{6}$ Kori et al.,${ }^{4}$ Lim et al., ${ }^{7}$ Selvaraj et al.,${ }^{8}$ Sumathi et al.,${ }^{9}$ Thapa et al. ${ }^{10}$

1.24; re-calculated RR, 0.89 ; $95 \%$ CI, 0.66 to 1.21$)$. The primary outcomes, as well as the sensitivity analysis, remained unaffected as the study was not included in the original analyses.

Lastly, we agree in principle that any post hoc protocol violation should generally be avoided. In our case, the PROSPERO update was taken after careful consideration, at the reviewer's requests, to enhance the clinical applicability of our study. The analyses of the severity of postoperative sore throat (POST) were added as it was an important clinical outcome to consider. The control group was widened to include no lubrications to reflect all current practices. We re-calculated our results after excluding studies with no-lubrication as the only control group, ${ }^{4-6}$ and studies that had no-lubrication as one of its control groups. $^{7-10}$ The RRs for POST-1 hr, POST-24 hr, POST moderate to severe (MS)-1 hr and POSTMS-24 $\mathrm{hr}$ remained insignificant (see Table 1 below).

Disclosures None.

Funding statement Department of Anesthesiology, Taipei Medical University Hospital.

Editorial responsibility This submission was handled by Dr. Hilary P. Grocott, Editor-in-Chief, Canadian Journal of Anesthesia.

\section{References}

1. Liao AH, Yeoh $S$, Lin $Y$, Lam $F$, Chen $T$, Chen $C l$. Lidocaine lubricants for intubation-related complications: a systematic review and meta-analysis. Can J Anesth 2019; 66: 1221-39.
2. Kataoka E. Uncertainty in the methods and interpretation of a meta-analysis of airway complications from lidocaine lubrication. Can J Anesth 2020. DOI: https://doi.org/10.1007/s12630-02001717-1.

3. Higgins JP, Thomas J, Chandler J, et al. Cochrane Handbook for Systematic Reviews of Interventions, version 6.0 (updated July 2019). Cochrane 2019. http://www.training.cochrane.org/ handbook (accessed May 2020).

4. Kori $K$, Muratani $T$, Tatsumi $S$, Minami $T$. Influence of endotracheal tube cuff lubrication on postoperative sore throat and hoarseness (Japanese). Masui 2009; 58: 342-5.

5. Basaranoglu G, Erden V, Delatioglu H. Postoperative sore throat: effect of lidocaine jelly and pomade on endotracheal intubation. J Clin Anesth 2004; 16: 79-80.

6. Klemola UM, Saarnivaara L, Yrjola H. Post-operative sore throat: effect of lignocaine jelly and spray with endotracheal intubation. Eur J Anaesthesiol 1988; 5: 391-9.

7. Lim CH, Kim JH, Jeaon EH, et al. The influence of succinylcholine and tracheal tube lubrication on postoperative sore throat. Korean J Anesthesiol 1996; 30: 542-8.

8. Selvaraj T, Dhanpal R. Evaluation of the application of topical steroids on the endotracheal tube in decreasing post-operative sore throat. J Anaesthesiol Clin Pharmacol 2002; 18: 167-70.

9. Sumathi PA, Shenoy T, Ambareesha M, Krishna HM. Controlled comparison between betamethasone gel and lidocaine jelly applied over tracheal tube to reduce postoperative sore throat, cough, and hoarseness of voice. Br J Anaesth 2008; 100: 215-8.

10. Thapa $P$, Shrestha RR, Shrestha $S$, Bajracharya GR. Betamethasone gel compared with lidocaine jelly to reduce tracheal tube related postoperative airway symptoms: a randomized controlled trial. BMC Res Notes 2017; DOI: https://doi.org/10.1186/s13104-017-2694-6.

Publisher's Note Springer Nature remains neutral with regard to jurisdictional claims in published maps and institutional affiliations. 